\title{
Body Dissatisfaction in Individuals with Obesity Compared to Normal-Weight Individuals: A Systematic Review and Meta-Analysis
}

\author{
Natascha-Alexandra Weinberger ${ }^{a, b}, c$ Anette Kersting $^{d}$ \\ Steffi G. Riedel-Heller ${ }^{b}$ Claudia Luck-Sikorski ${ }^{a}$ b, c \\ a Leipzig University Hospital, Integrated Research and Treatment Center (IFB) \\ AdiposityDiseases, Leipzig, Germany; ${ }^{b}$ Institute of Social Medicine, Occupational Health and

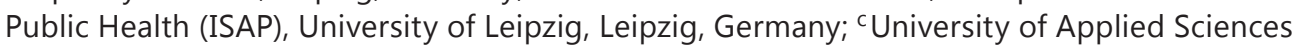 \\ SRH Gera, Gera, Germany; ${ }^{d}$ Department of Psychosomatic Medicine and Psychotherapy, \\ University of Leipzig, Leipzig, Germany
}

\section{Key Words}

Obesity · Body image · Body dissatisfaction · BMI groups · Adults

\begin{abstract}
Background: Body dissatisfaction has been identified as a psychological correlate of obesity that is related to disordered eating, poor self-esteem, and depression. However, not all individuals with obesity are equally vulnerable to these correlates, and 'normative discontent' is present in individuals with normal weight, too. In this light, the complex relationship of body image and individual weight status seems like a worthwhile direction of research inquiry. As such, this review aims to systematically explore the degree of body dissatisfaction in individuals with obesity compared to normal-weight individuals. Methods: A systematic literature search was conducted. All quantitative studies of adult samples reporting results regarding differences in body dissatisfaction between individuals with normal weight and obesity were included. Results: 17 articles were found. Across studies, individuals with obesity reported higher body dissatisfaction than normal-weight individuals (questionnaires: $d=0.89,95 \% \mathrm{CI}$ $=0.63-1.16, p<0.001$; silhouette scales: $d=1.41,95 \% C I=0.57-2.25, p<0.001$ ). Meta-regression revealed a significant association of female gender and higher body dissatisfaction $(b=0.60, p=0.007)$. Conclusion: The findings underline the severity of body dissatisfaction among individuals with obesity and especially among women. Future research recommendations are discussed.

(c) 2016 The Author(s)

Published by S. Karger GmbH, Freiburg
\end{abstract}


Weinberger et al.: Body Dissatisfaction in Individuals with Obesity Compared to Normal-Weight Individuals: A Systematic Review and Meta-Analysis

\section{Introduction}

Obesity is widely considered to be one of the most serious public health problems of recent times, not only increasing health care costs and risk of illness but also burdening individuals with obesity with severe psychological consequences [1]. Next to self-esteem and emotional well-being, body image is a key concept believed to be negatively affected in obesity [2].

Body image is a multidimensional construct and refers to a person's perceptions and attitudes, including feelings, thoughts and behaviors, regarding their own body and appearance [3]. According to this cognitive-behavioral model of body image, personality and physical attributes as well as interpersonal attributes and cultural socialization all play a role in how invested individuals are in their body image and how they evaluate it [4].

One facet of attitudinal body image is referred to as body satisfaction or body dissatisfaction [5]. It describes the subjective evaluation of the degree to which an individual has a positive or negative regard for their body [6].

Similarly to the concept itself, measurement of body image is multidimensional as well, a circumstance that explains why, e.g., weight dissatisfaction does not necessarily imply body dissatisfaction [7]. Assessment tools generally include perceptual accuracy of or attitudes regarding body image like subjective satisfaction, investment in appearance and beliefs about the body, and avoidance behavior [8]. While the former tend to make use of figural drawing scales and computer morphing techniques, the latter is often assessed using self-report questionnaires $[9,10]$.

The link between weight status and body image is complex. Schwartz and Brownell [11] argue that body image might be affected by obesity through psychological distress, which has an impact on quality of life. As outlined above, while body image is a subjective psychological phenomenon, it is also largely determined by social experiences [12]. Current Western societies tend to idealize slenderness, and it is assumed that media portrayal of the ideal female or male body has great influence on the way individuals evaluate and experience their physical appearance [13]. These ideals are generally associated with being strong-willed and in control of one's body, and individuals not able to conform to this ideal face substantial stigma [12]. While the focus in women is on being thin, men are supposed to be moderately muscular as well [14]. Past research has indeed found women to be more likely to strive for thinness [15]. Interestingly, men seem to be split between those wanting to be thinner and those who wish to be larger and more muscular [14], a distinction that lead to recommendations of investigating male and female body dissatisfaction separately from each other [16].

In light of the negative preconceptions that come with not meeting society's bodily ideals, it seems unsurprising that body dissatisfaction is particularly prevalent in individuals with overweight or obesity [17] and sometimes even related to eating disorders [18]. However, it seems that not all persons with obesity are equally vulnerable to this problem: Previous evidence indicates lower prevalence of body image concerns in individuals with obesity who are not seeking treatment in comparison to those who are $[19,20]$. Moreover, individuals with normal weight are far from satisfied with their body shape or size, a circumstance so widespread among women that it has aptly been labeled as a 'normative discontent' [21] which reaches well into older age categories [15, 22].

A number of individual studies have reported findings on body dissatisfaction in samples of various weight statuses. Further, research has consistently found women to be more dissatisfied with their body than men $[23,24]$. No comprehensive review, however, has quantified differences in body dissatisfaction between individuals with normal weight and obesity up to date. While this difference is commonly assumed, the magnitude of the problem still needs to be determined. To gain a more comprehensive picture of this issue, this systematic review 
Weinberger et al.: Body Dissatisfaction in Individuals with Obesity Compared to

Normal-Weight Individuals: A Systematic Review and Meta-Analysis

aims to systematically explore the degree of body dissatisfaction of individuals with obesity compared to individuals with normal weight. Moreover, gender differences in body dissatisfaction across studies are analyzed.

\section{Material and Methods}

This review was prepared according to the systematic literature review guidelines of the Centre for Reviews and Dissemination [25] and follows PRISMA (Preferred Reporting Items for Systematic Reviews and Meta-Analyses) suggestions [26].

Eligibility Criteria

Eligible for inclusion in the systematic review were published articles in which an assessment of body image was conducted and in which a quantitative outcome regarding differences in body image between adults with normal weight and obesity was reported. The weight groups were defined according to the BMI cut-off criteria of the WHO [27]. Journal articles published in English before December 2015 were eligible for inclusion.

\section{Information Sources}

We searched the electronic databases Medline 1970 to present, Web of Science 1970-2015, PsycINFO 1970-2015, and Cochrane Library 1970-2015. Relevant secondary references from the bibliographies of the selected articles were searched as well.

Search

A systematic literature search was carried out using the following strategy: ['obesity' OR 'overweight'] AND ['body image' OR 'body dissatisfaction' OR 'body satisfaction' OR 'body image*'].

\section{Study Selection}

The first stage of screening was conducted by one author. Here, papers which were clearly not studies about body image or quantitative studies, or about adult samples were excluded on the basis of title and abstracts alone. In the second stage, full texts were obtained for the remaining records and screened by two authors.

Papers were rejected which were not published in the English language, not conducted using a normalweight comparison group, did not include participants with obesity, and did not report separate outcomes for participants with overweight and obesity. Taking previous findings into consideration that hint at potential differences in body dissatisfaction among subgroups [19,20], articles which focused on participants of weight loss, weight maintenance or weight management interventions, focused on bariatric surgery patients or patients undergoing treatment/therapy of obesity/binge eating/eating disorders, or included/ focused on pregnant women were excluded. Also, papers were rejected which did not report separate, quantifiable outcomes for the group with obesity and the comparison group. Further, to account for the multidimensional nature of the body image construct, papers were excluded which did not focus on body dissatisfaction in particular. Finally, duplicates, conference papers, editorials as well as review articles and book chapters were rejected.

Eligible papers were tabulated and used in the qualitative synthesis. Criteria for inclusion in the metaanalysis were more restrictive. Studies with a sample size $\leq 10$ in any of the weight groups and studies using single items to assess body dissatisfaction were excluded. Further, papers not reporting separate data for women and men or not reporting data necessary to calculate effect size (standardized differences in means) were not included in the meta-analyses.

\section{Data Collection Process}

Data relevant for the review and meta-analyses were collected in a datasheet. Two corresponding authors were contacted via email for further information. The first author was asked to provide the numerical data of two figures illustrating the percentage of participants dissatisfied with their weight. This paper was excluded after the detailed final analysis due to its focus on weight dissatisfaction. The second author was asked for the exact number of participants in each of the weight groups for the female and male sample. Since we did not receive a response, the paper was not included in the meta-analysis. 
Weinberger et al.: Body Dissatisfaction in Individuals with Obesity Compared to Normal-Weight Individuals: A Systematic Review and Meta-Analysis

Data Items

The following characteristics were extracted from the original articles and included in the review: lead author, year of publication, country of origin of the sample, sample size, age, sex, BMI assessment method, and body image measure as well as outcomes of body dissatisfaction (e.g., mean, SD, percentages) and effect size. For an overview see tables 1 and 2.

Risk of Bias in Individual Studies

A tool similar to the risk-of-bias assessment tool outlined in the Cochrane Handbook for Systematic Reviews of Interventions [28] was created to account for the most common factors influencing body image assessment [11]. The author reviewed the following aspects of all included studies: i) control for gender, ii) control for ethnicity of sample, iii) control for weight-control behavior, iv) control for comorbidities (e.g., eating disorders, depression, or personality disorders), and v) assessment of other body image facets (e.g., appearance investment).

\section{Data Analysis}

Statistical analyses were performed using the statistical software Comprehensive Meta-Analysis, version 3.0 (Biostat, Englewood, NJ, USA) and STATA 13.1 using the metan and metareg commands. The standardized differences in means with standard errors were calculated for relevant body dissatisfaction outcomes for the group with obesity and the group with normal weight. A random-effects model of analysis was used, and heterogeneity among the included studies was assessed by determining the Cochran Q and the $\mathrm{I}^{2}$ statistic. For Cochran $\mathrm{Q}$, a p value $<0.10$ indicated statistically significant heterogeneity. For $\mathrm{I}^{2}$, the percentage of observed between-study variability due to heterogeneity rather than chance was used as an indicator. No heterogeneity was indicated by $0-30 \%$, moderate heterogeneity was indicated by $30-50 \%$, substantial heterogeneity was indicated by $50-75 \%$, and considerable heterogeneity was indicated by $75-100 \%$. Pooled standardized differences in means for all outcomes were calculated. A two-sided $\mathrm{p}$ value $<$ 0.05 was taken to indicate statistical significance.

\section{Results}

A total of 17 studies were identified for inclusion in the review, and 14 studies met the stricter inclusion criteria for the meta-analyses. The studies excluded from the meta-analyses either used single items to assess body dissatisfaction or had a sample size of 10 or less in any of the weight groups or did not report data necessary to calculate standardized differences in means [29-31]. The study selection process is illustrated in figure 1.

\section{Characteristics of Included Studies}

The characteristics of the studies meeting the eligibility criteria are summarized in table 1.

Overall, the included studies involved 13,508 participants and varied in their samples' country of origin and analyzed ethnic groups. Gender-specific data were present in 16 of the 17 papers. The majority of studies focused on body image and related topics such as prevalence of overweight and obesity, or BMI and body composition. Five studies assessed and reported body image but also focused on a different topic, e.g. narcissism or sexuality [29, 32-35].

The reviewed papers relied on different methods to assess body dissatisfaction. Nine studies made use of generally established and validated self-report questionnaires like the Multidimensional Body-Self Relations Questionnaire (MBSRQ) [36]; for an overview of body satisfaction instruments [8]. Morotti and colleagues [29] measured body dissatisfaction with two single items, Baceviciene and colleagues [37] used the body image subscale of the WHO Quality of Life Scale. Moreover, two studies had subjects complete body image scales developed by the respective authors [34, 38]. Further, four studies used figure rating scales and had 
Weinberger et al.: Body Dissatisfaction in Individuals with Obesity Compared to

Normal-Weight Individuals: A Systematic Review and Meta-Analysis

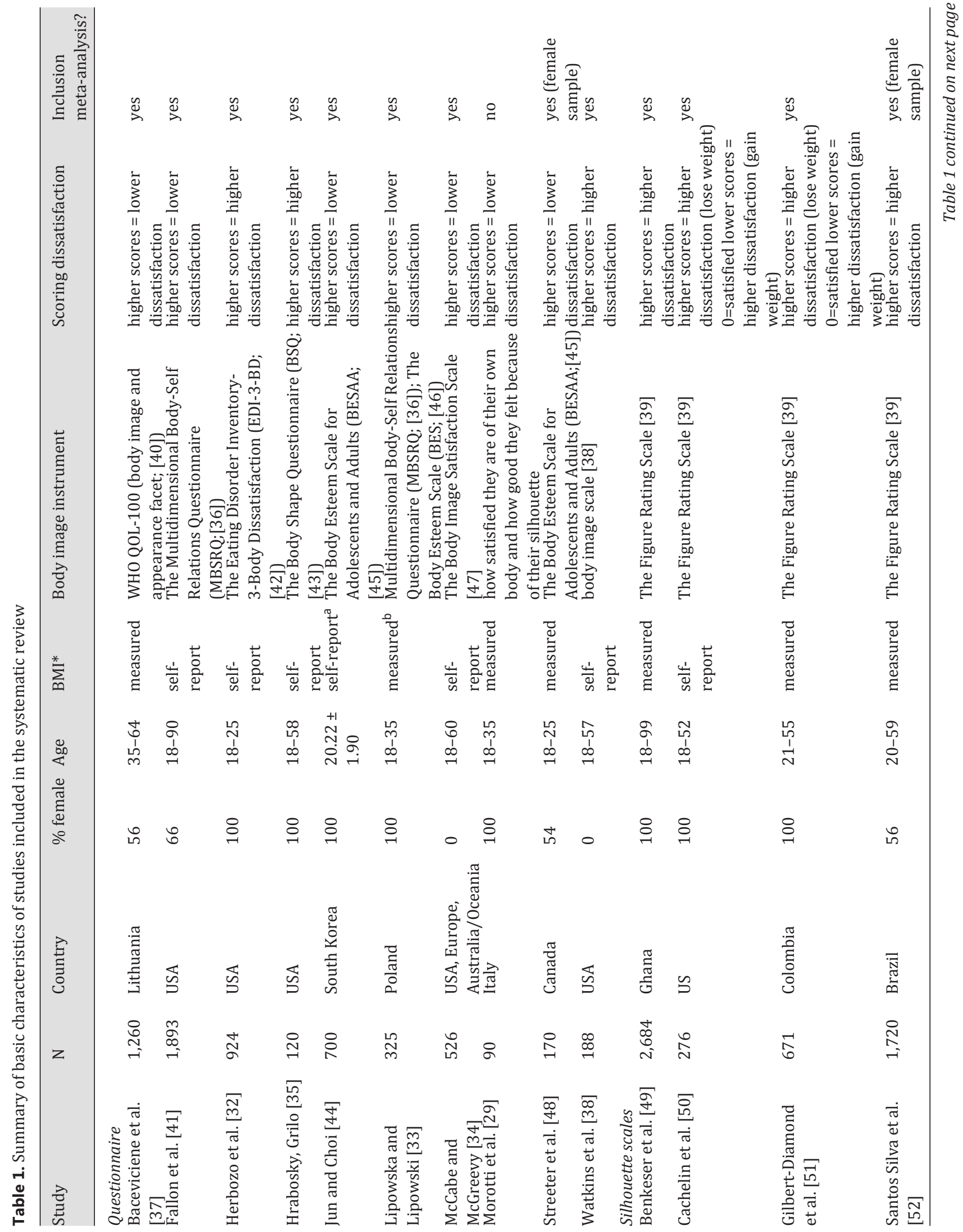


Weinberger et al.: Body Dissatisfaction in Individuals with Obesity Compared to Normal-Weight Individuals: A Systematic Review and Meta-Analysis

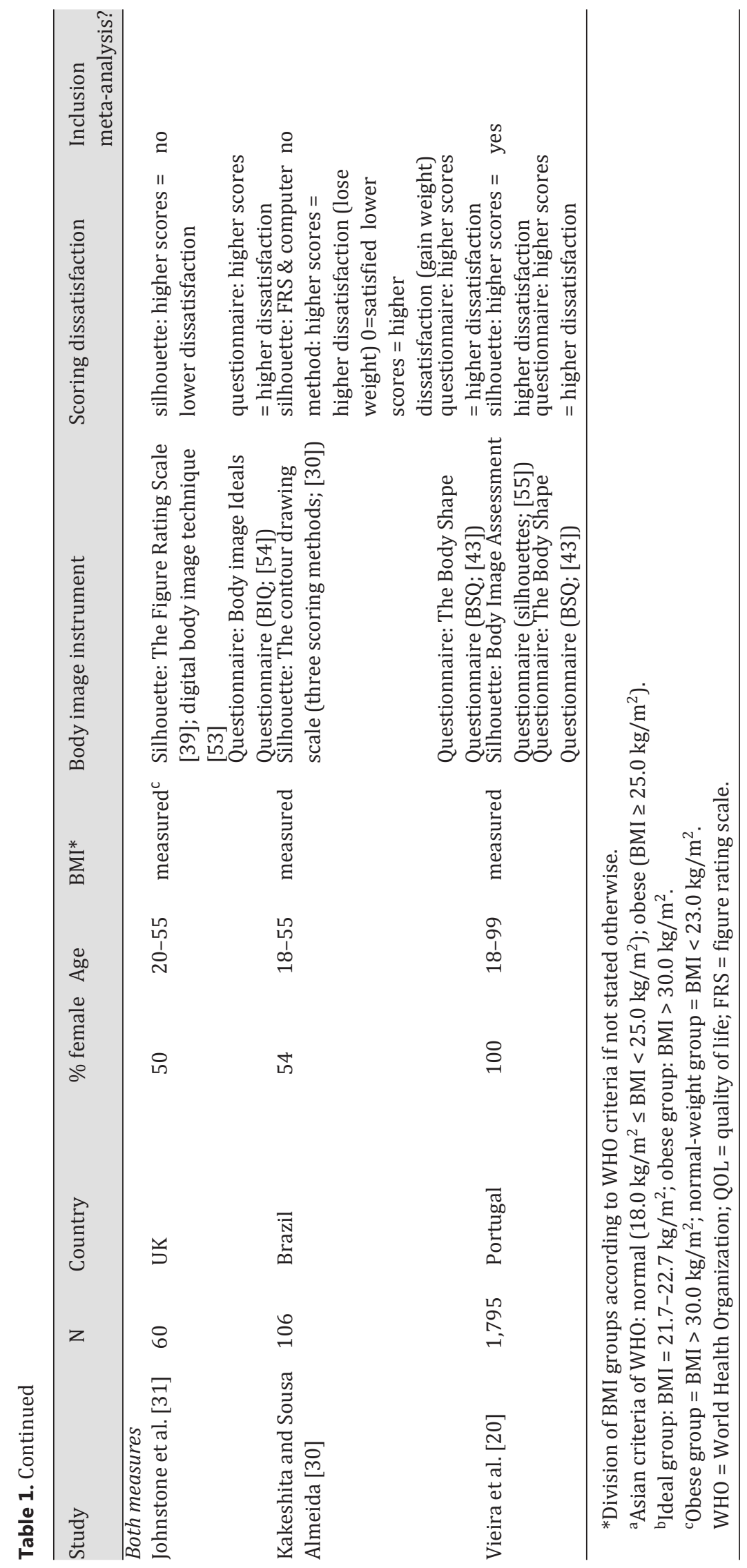




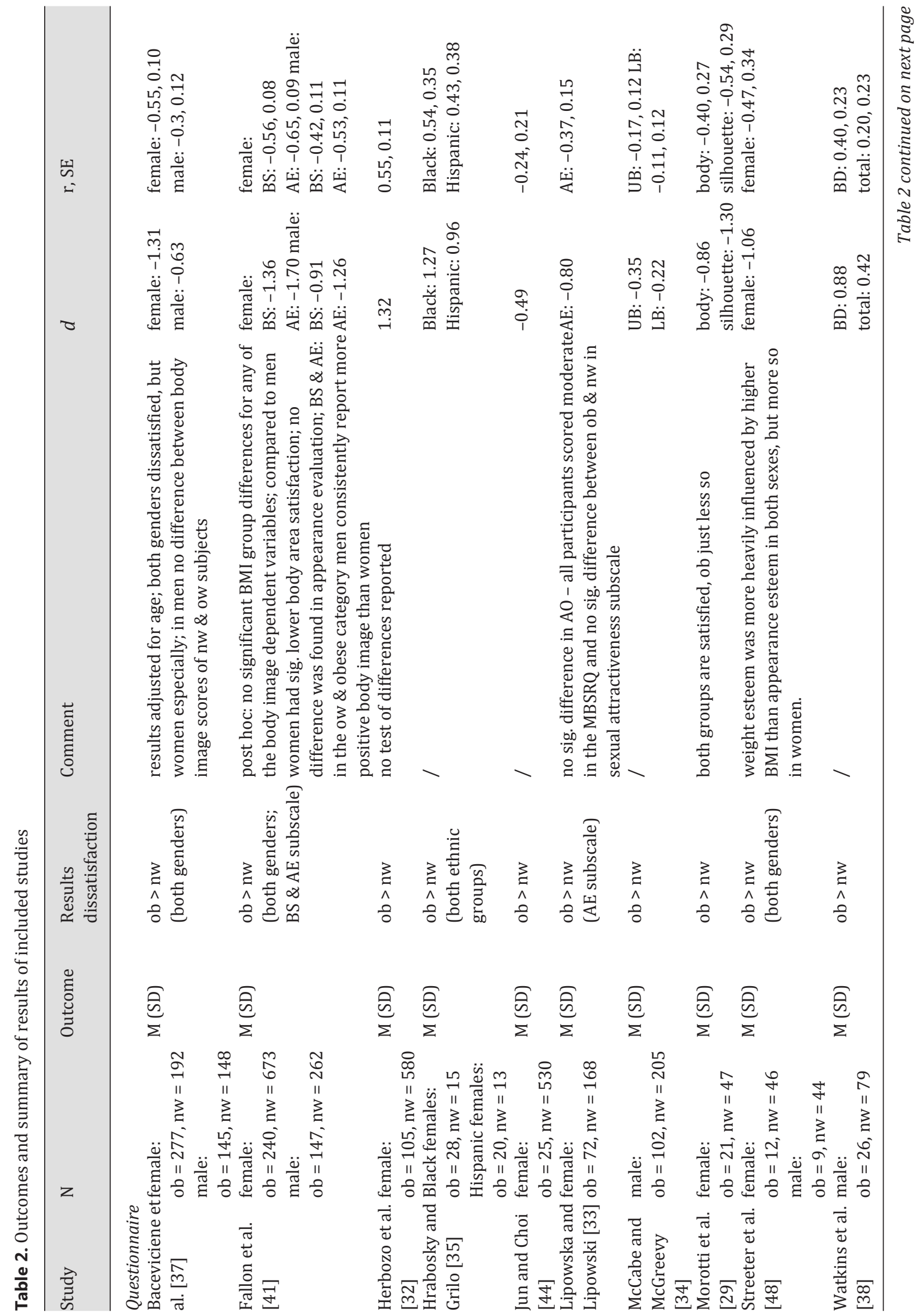


Weinberger et al.: Body Dissatisfaction in Individuals with Obesity Compared to Normal-Weight Individuals: A Systematic Review and Meta-Analysis
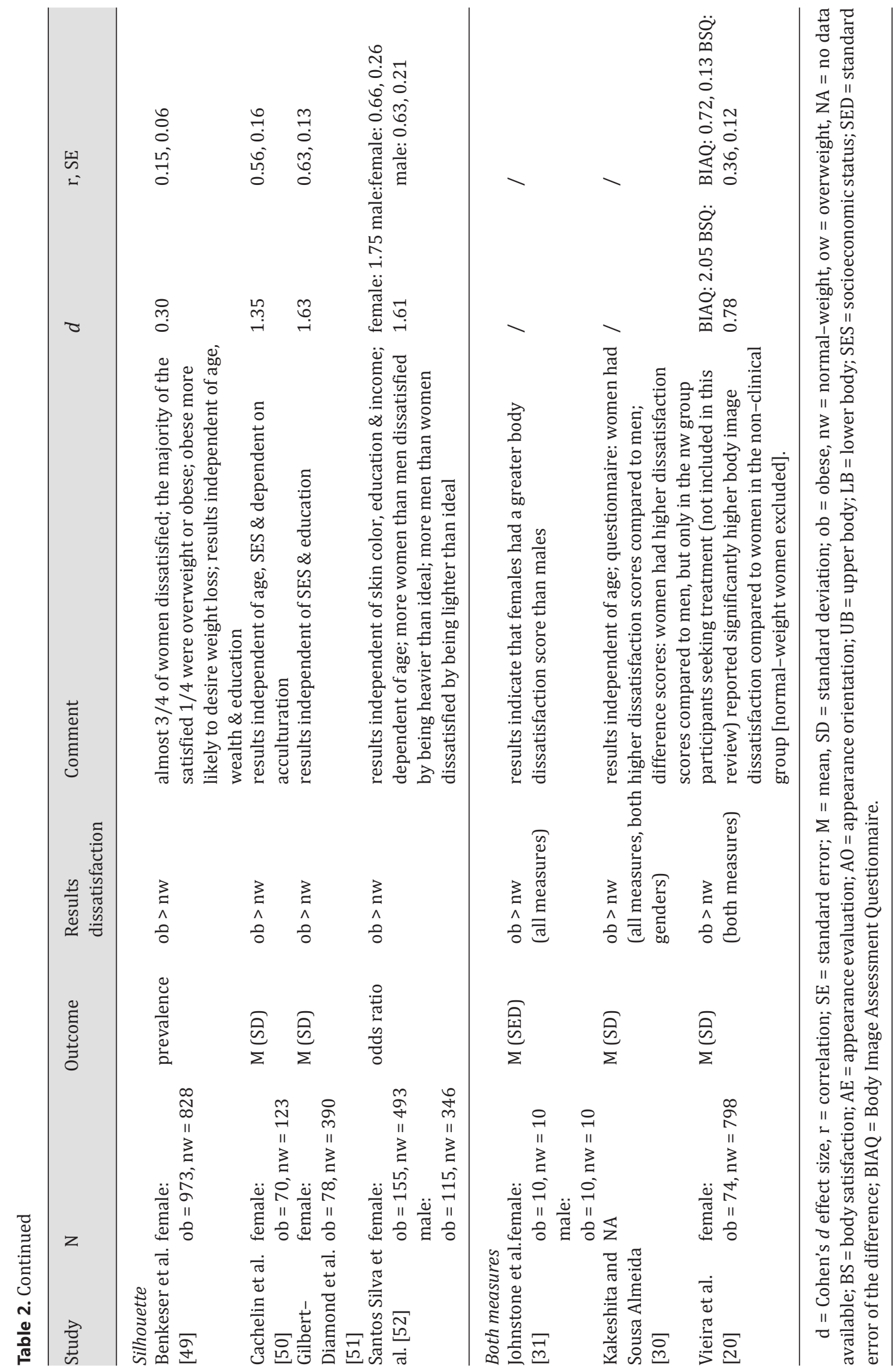
Weinberger et al.: Body Dissatisfaction in Individuals with Obesity Compared to Normal-Weight Individuals: A Systematic Review and Meta-Analysis

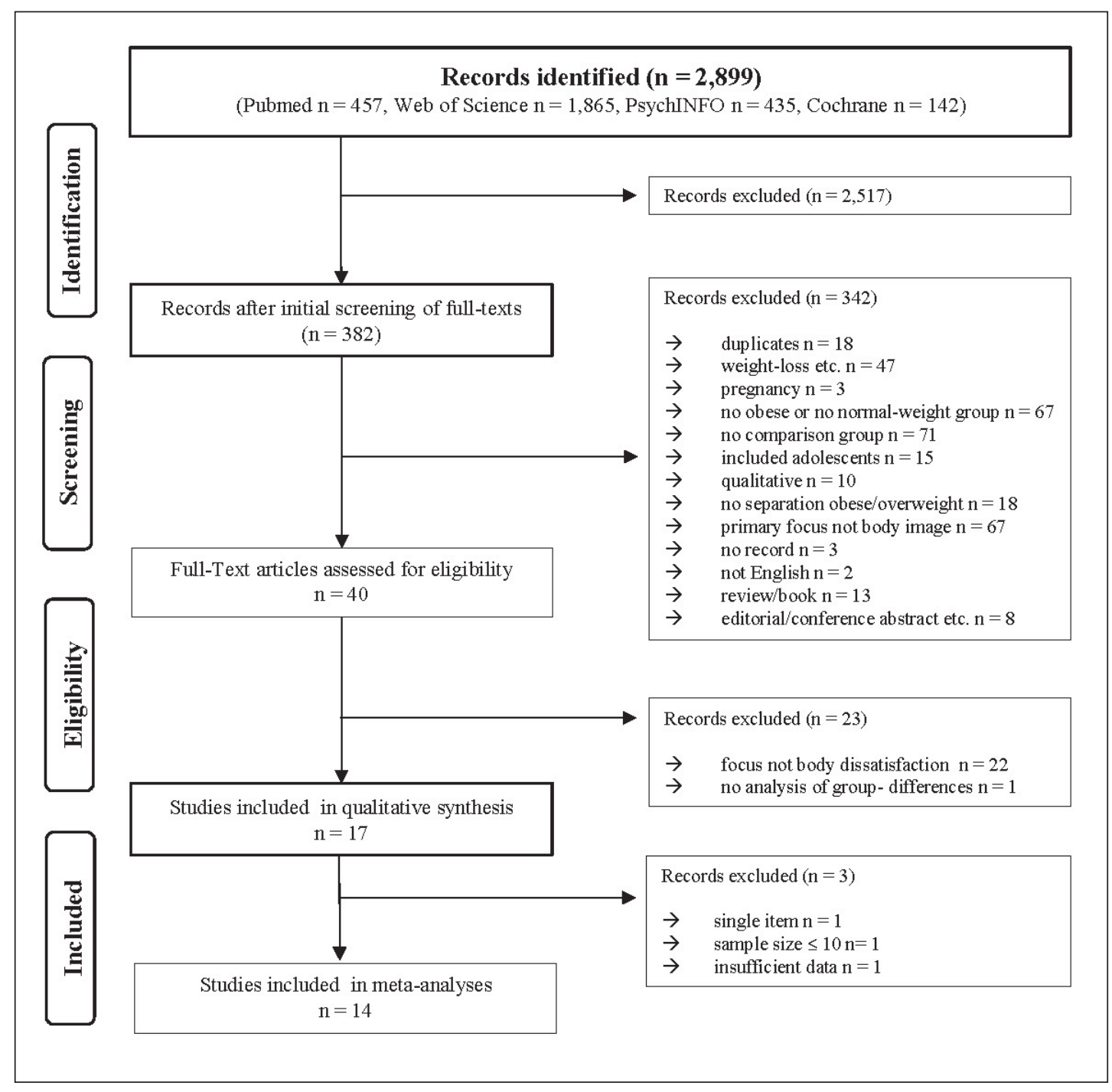

Fig. 1. Flow diagram of study selection. Adapted from [26].

participants chose the silhouette that represented how they would like to look (ideal) and how they currently look (current). Body dissatisfaction was then measured by calculating the difference between ideal and current silhouette, with greater discrepancies indicating greater dissatisfaction [39]. In addition to a body image questionnaire, two studies used figure drawing scales [20,30]. One study made use of a digital body image technique comparing both a figure drawing scale and a questionnaire [31].

Finally, while the majority of studies using figure drawing scales measured participants' weight and height, studies using self-report questionnaires often relied on the subjects' selfreported anthropomorphic data (table 1).

\section{Results of Individual Studies and Quality Assessment}

Across the studies, individuals with obesity reported higher body dissatisfaction than individuals with normal weight. Notably however, Lipowska and Lipowski [33] found no significant difference between women with obesity and women with normal weight in their 
Weinberger et al.: Body Dissatisfaction in Individuals with Obesity Compared to

Normal-Weight Individuals: A Systematic Review and Meta-Analysis

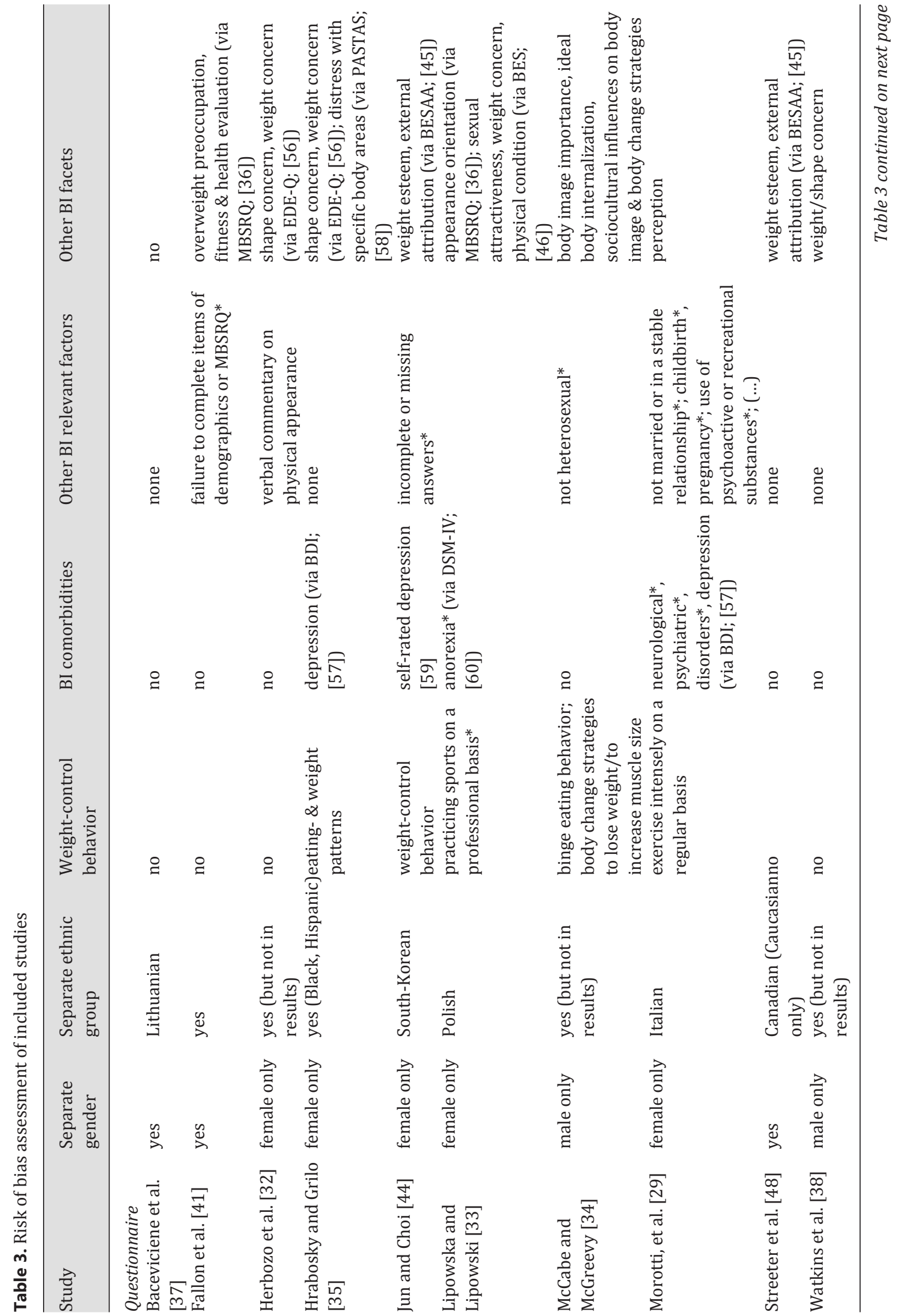


Weinberger et al.: Body Dissatisfaction in Individuals with Obesity Compared to Normal-Weight Individuals: A Systematic Review and Meta-Analysis
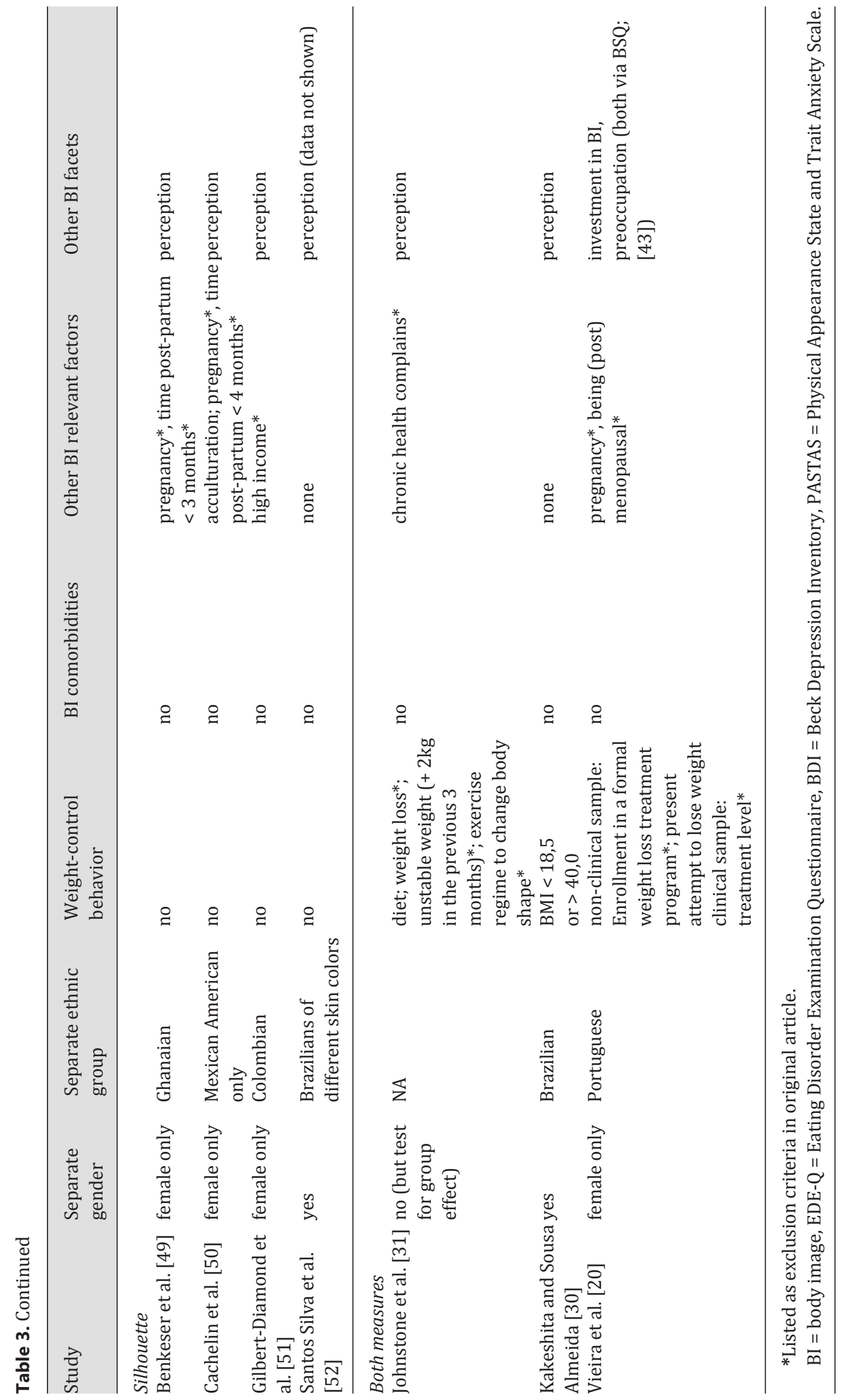
estimation of their sexual attractiveness. They also note that all participants scored moderate in the MBSRQ and subjects of both groups did not differ in the extent of investment their appearance. Moreover, Morotti and colleagues [29] reported both groups to be satisfied, with obese women being more dissatisfied. Further, Benkeser and colleagues [49] found threequarters of their sample to be dissatisfied with their body. Interestingly, the majority of the subjects reporting satisfaction with their body were overweight or obese.

Regarding gender differences, women generally reported being more dissatisfied with their body image than men [30,31]. In addition, Fallon and colleagues [41] found men with overweight and obesity to consistently report more positive body image than women in both body area satisfaction and the appearance evaluation. Similarly, Baceviciene and colleagues [37] report both genders to be dissatisfied, particularly the women. They also found no difference between body image scores of male subjects with normal weight and overweight. Further, Streeter and colleagues [48] found weight esteem to be more heavily influenced by higher BMI than appearance esteem in both sexes, but again more so in women. Santos Silva and colleagues [52] report more women than men to be dissatisfied by being heavier than ideal, but more men than women being dissatisfied by being lighter than ideal.

Per assessment method, an overview of body dissatisfaction results is provided in table 2 .

All of the studies controlled for gender, and a majority either analyzed only one or reported separate results for different ethnic groups. Moreover, in the majority of questionnaire studies, body image dissatisfaction was assessed using validated instruments that accounted for the multidimensionality of the construct. Although all studies reported inclusion or exclusion criteria as well as control variables, body image-related influence factors such as eating disorders could not be fully ascertained for all of them. Particularly, weight control behavior and comorbidities such as eating disorders and depression were not collected in a large proportion of studies. The details of the risk-of-bias assessment are illustrated in table 3 .

\section{Synthesis of Results}

Questionnaires Body Dissatisfaction

A random-effects model of analysis was used and significant heterogeneity was found $\left(\mathrm{Q}=117.12, \mathrm{df}=10, \mathrm{p}<0.001 ; \mathrm{I}^{2}=91.5 \%\right)$. The overall analysis showed body dissatisfaction to significantly afflict the group with obesity over the normal-weight group (pooled standardized difference in means $=0.89,95 \% \mathrm{CI}=0.63-1.16, \mathrm{p}<0.001$ ). Based on the literature, we decided to conduct gender-specific analyses as shown in figure 2 .

The pooled effect size of body dissatisfaction for men was $0.58(95 \% \mathrm{CI}=0.31-0.85)$ compared to 1.18 (95\% CI $=0.97-1.40)$ in women. Subsequent meta-regression revealed a significant association of female gender and higher body dissatisfaction $(b=0.60, p=0.007)$.

\section{Questionnaires Appearance Evaluation}

Four studies assessed Appearance Evaluation in women. Again, significant heterogeneity $\left(\mathrm{Q}=49.4, \mathrm{df}=4, \mathrm{p}<0.001, \mathrm{I}^{2}=93.3 \%\right)$ existed, and a random-effects model was run. The overall effect size was $1.02(95 \% \mathrm{CI}=0.37-1.67)$.

Figure Drawing Scales

Four studies assessed body dissatisfaction in women with a figure drawing scale. A random-effects model of analysis was used, and significant heterogeneity was found $(\mathrm{Q}=$ $231.5, \mathrm{df}=4, \mathrm{p}<0.001 ; \mathrm{I}^{2}=98.3 \%$ ). The overall analysis showed body dissatisfaction to significantly more afflict the group with obesity than the normal-weight group (pooled standardized difference in means $=1.41,95 \% \mathrm{CI}=0.57-2.25, \mathrm{p}<0.001$ ). 
Weinberger et al.: Body Dissatisfaction in Individuals with Obesity Compared to Normal-Weight Individuals: A Systematic Review and Meta-Analysis

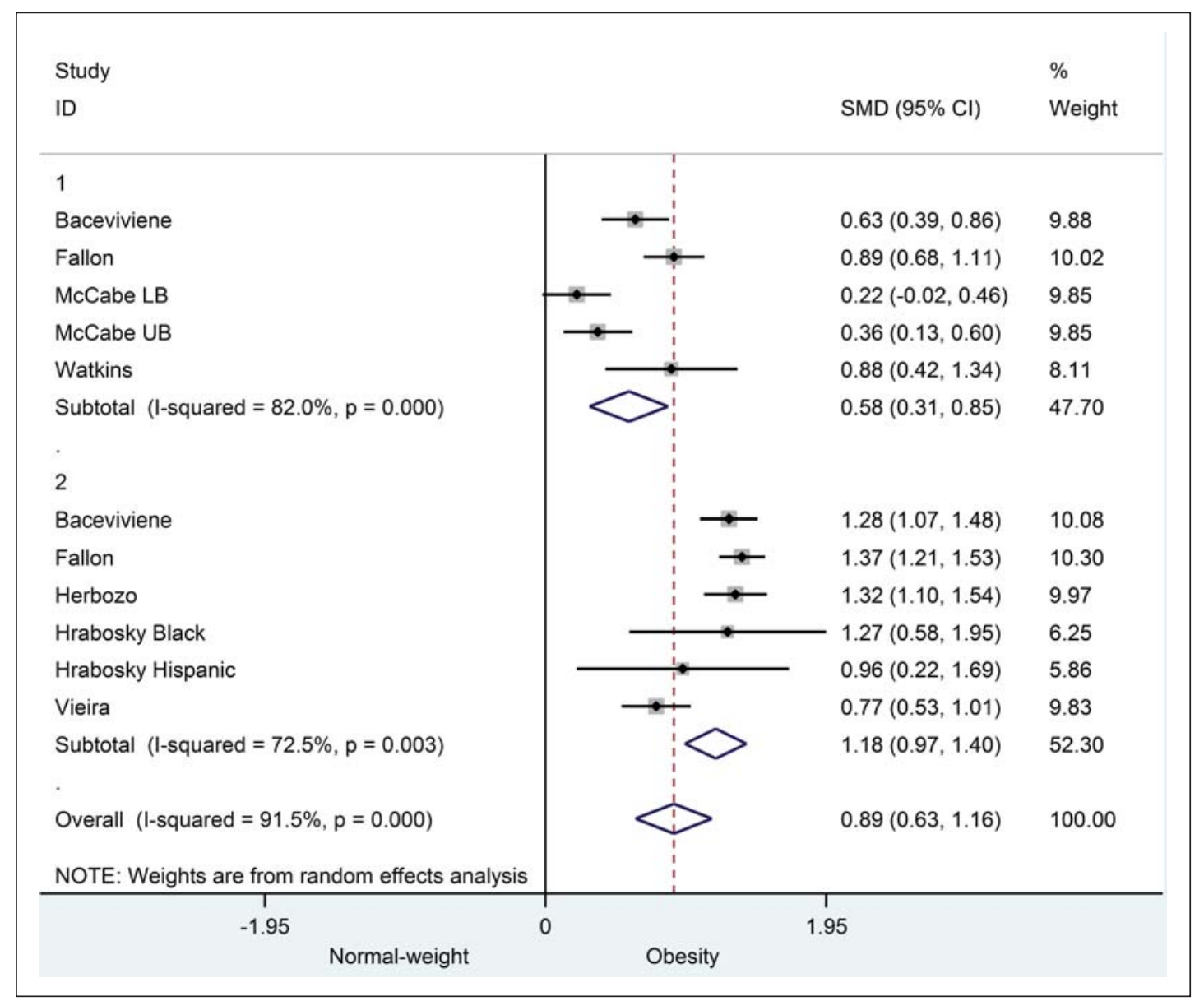

Fig. 2. Meta-analysis of differences in body dissatisfaction questionnaire scores between individuals with obesity and normal-weight among male and female samples. Abbreviations: 1 = male; 2 = female; SMD = standardized mean difference; $\mathrm{CI}$ = confidence interval; $\mathrm{LB}=$ lower body; $\mathrm{UB}=$ upper body.

Risk of Bias across Studies

Considering that each meta-analysis performed included less than 10 studies, no sensitivity analysis or assessment of publication bias was performed.

\section{Discussion}

This review aimed at systematically exploring the degree of body dissatisfaction in individuals with obesity compared to individuals with normal weight as well as analyzing gender differences in body dissatisfaction across studies. In total, 17 studies met the eligibility criteria for inclusion, and 14 of them provided suitable data for meta-analysis. Meta-analyses showed body dissatisfaction to significantly more afflict the group with obesity than the normalweight group in both studies using questionnaires as well as in those using figure drawing scales. Further, participants with obesity rated their bodily appearance significantly more negative in comparison to normal-weight participants. Effect sizes ranged from small to large in the male samples $(d=0.22-0.89)$ and from medium to large in the female samples $(d=$ 
Weinberger et al.: Body Dissatisfaction in Individuals with Obesity Compared to Normal-Weight Individuals: A Systematic Review and Meta-Analysis

0.77-1.37). The meta-regression revealed the difference in body dissatisfaction between women with obesity and normal weight to be significantly higher than in men.

The two major results of the current systematic review and meta-analyses seem to be in line with past findings on the topic: body dissatisfaction is greater in persons with obesity than in normal-weight persons, and compared to their respective normal-weight peers, women with obesity are more dissatisfied with their bodies than men with obesity. These differences appear hardly surprising considering that societies' emphasis on thinness and beauty particularly affect girls and women [12]. Accordingly, past research shows that physical appearance seems to be of more importance to females than males [61]. Moreover, women report significantly higher body dissatisfaction, even if their BMIs are lower than those of men [62]. This finding was affirmed by a recent cross-national study that reports that $25 \%$ of girls were undertaking some measure to lose weight, like dieting, and that they were more likely to think of themselves as 'fat' even though overweight and obesity was higher in boys [63] Furthermore, a number of studies have concluded that body dissatisfaction in women seems to be stable across the life span [15].

Due to past research having focused on women, the picture of body dissatisfaction in men is less clear and as such the subject of a rising number of studies. McCreary and Sasse [64] for example report that men and boys also seem to increasingly report body dissatisfaction and that body image is a concern for males over the lifespan [14]. Similarly to women, body dissatisfaction in men is linked to low self-esteem, depression, and eating disorders [65], but also to the use of bodybuilding drugs like anabolic steroids or human growth hormone [66]. Moreover, it is hypothesized that males with overweight or obesity might protect themselves from body dissatisfaction by considering themselves as 'big and strong' rather than 'fat' [11].

As a consequence, nuanced approaches to further investigate the relationship between male gender, weight status and body image are required.

Regarding body dissatisfaction in populations with obesity, our findings are in accordance with previous assumptions, especially concerning women with obesity $[11,19]$. Interestingly, not all studies of women with obesity find a relationship between BMI and body dissatisfaction [8]. Certain factors like weight-related teasing or stigmatizing experiences appear to play a role in increased body image concerns in this population as well [67].

An important practical implication of these negative obesity-related consequences pertains to treatment options. Schwartz and Brownell [11] theorize that many individuals with obesity might consider weight loss to be the optimal way to improve their body image. Generally, studies examining body image before and after weight loss treatment find improved body image as a person loses weight and deterioration if the individual regains weight [68]. One particular exception constitutes massive weight loss following bariatric surgery: Body dissatisfaction due to hanging skin is common and often entails body contouring surgery to alleviate this 'new' dissatisfaction [69]. However, individuals with extreme obesity seeking bariatric surgery underscore the importance of body dissatisfaction as a motivating factor as these individuals are impelled by improvements in appearance rather than improvements in health [8]. Moreover, previous research suggests that, unlike the experience of stigma and discrimination, a certain level of body dissatisfaction might motivate healthy behavior changes like increased physical activity [70]. In turn, improved body image is theorized to facilitate use of psychosocial resources and lead to better adherence to weight management [71].

Thus, intervention and prevention measures that also take into account the heterogeneity of the population with obesity seem to be a promising approach to not only mitigate negative psychological consequences but also - due to body dissatisfaction's association with vital health behaviors - contribute in the treatment against obesity itself. 
Weinberger et al.: Body Dissatisfaction in Individuals with Obesity Compared to Normal-Weight Individuals: A Systematic Review and Meta-Analysis

Naturally, the current review has limitations. The number of studies that we were able to include is limited. It seems likely that studies reporting null findings or results contradicting the general consensus might have been susceptible to publication bias. Moreover, the current research does not include papers not written in English. Considering the rising prevalence of obesity in developing nations and cultural differences in body image that may be a promising approach for prevention and intervention measures [50], insufficient inclusion of potential findings regarding body image among samples of different ethnicities is particularly unfortunate.

As with any overview, the samples and assessment tools are not identical across studies. Especially, the use of different measures to determine body dissatisfaction makes comparisons rather difficult. While some studies used validated scales, others relied on single items or figure rating scales to assess body dissatisfaction. Even though past research has shown high correlations between figure rating scores and body dissatisfaction questionnaires [72], not all lines of action of psychological research assume self and ideal ratings to be distinct causes of body dissatisfaction [73]. Next to conceptual differences, there is also debate regarding the use of difference scores as a measure of body image due to potential methodological problems like ambiguity or dimensional reduction (see [74] for details).

Further, we agree with past studies that encourage researchers to make use of measures developed for and validated in samples with obesity [10].

Another critical point pertains to the assessment of anthropometric data (particularly subjects' height and weight). The majority of included studies used self-reported height and weight data to calculate BMI and determine consequent group assignment. However, while self-report data may be more time- and cost-effective in comparison to measurement of weight and height, research shows trends of participants underestimating their weight and BMI and overestimating their height [75]. This is particularly problematic if the self-reported BMI is a primary variable of interest and used for example in classification of BMI groups or evaluations of prevalence of obesity or overweight [76]. Thus, the use of measured anthropometric data is recommended especially in studies analyzing participants with overweight and obesity [77].

Moreover, possible influences of comorbid conditions in the included studies could not be controlled for completely. As illustrated in table 3, not all studies explicitly excluded participants engaging in weight control behavior or seeking or already undergoing treatment for weight management. In addition, comorbidities like eating disorders or depression were not controlled for in all included papers, making conclusions about potential differences in body dissatisfaction between subsamples with and without comorbid conditions extremely difficult. Taken together with the fact that the majority of studies analyzed a sample that was not representative of the respective population, the current findings should be interpreted with care.

The current review is the first to attempt to quantify differences in body dissatisfaction between individuals with normal weight and obesity. As such, it gives a first estimation as to the magnitude of the problem. Our results underline the severity of body dissatisfaction among individuals with obesity and especially among women.

This is particularly concerning since the prevalence of obesity is increasing worldwide [78] and consequently puts more individuals at risk of suffering its negative physical and psychological consequences. As outlined above, interventions to improve body image are not just beneficial to obesity management but also to psychological well-being in general. Considering that body dissatisfaction and body perception are associated with partly unfavorable obesity-related behaviors, like excessive weight loss attempts and binge eating [79], not just the development of prevention and intervention measures but also their implication in practice is essential. Furthermore, to account for the complexity of the issue in this group, 
Weinberger et al.: Body Dissatisfaction in Individuals with Obesity Compared to Normal-Weight Individuals: A Systematic Review and Meta-Analysis

more research regarding body image in men and particularly in men with obesity is required. Also, in light of its multidimensionality, a closer look at other body image facets like body image perception and their relationship with individual's weight status seems worthwhile. Finally, future research on the topic should also include and analyze individuals of different classes of obesity.

\section{Funding}

This work was supported by the Federal Ministry of Education and Research (BMBF), Germany, FKZ: 01E01501.

\section{Disclosure Statement}

All authors declare no conflict of interest.

\section{References}

1 Friedman MA, Brownell KD: Psychological correlates of obesity: moving to the next research generation. Psychol Bull 1995;117:3-20.

2 Wardle J, Cooke L: The impact of obesity on psychological well-being. Best Pract Res Clin Endocrinol Metab 2005;19:421-440.

3 Cash TF: Body image: past, present, and future. Body Image 2004;1:1-5.

4 Cash TF: Body image: Cognitive behavioral perspectives on body image; in Cash TF, Pruzinsky T (eds): Body Images: A Handbook of Theory, Research, and Clinical Practice. New York, Guilford Press, 2002, pp 38-46.

5 Cash TF: Body-image attitudes: evaluation, investment, and affect. Percept Mot Skills 1994;78:1168-1170.

6 Pole M, Crowther JH, Schell J: Body dissatisfaction in married women: the role of spousal influence and marital communication patterns. Body Image 2004;1:267-278.

7 Flynn KJ, Fitzgibbon M: Body images and obesity risk among black females: a review of the literature. Ann Behav Med 1998;20:13-24.

8 Sarwer DB, Thompson JK, Cash TF: Body image and obesity in adulthood. Psychiatr Clin North Am 2005;28: 69-87.

9 Gardner RM, Brown DL: Body image assessment: a review of figural drawing scales. Personality and Individual Differences 2010;48:107-11.

10 Pull CB, Aguayo GA: Assessment of body-image perception and attitudes in obesity. Curr Opin Psychiatry 2011;24:41-48.

11 Schwartz MB, Brownell KD: Obesity and body image. Body Image 2004;1:43-56.

12 Grogan S: Body Image: Understanding Body Dissatisfaction in Men, Women and Children, 2nd ed. New York, Routledge, 2008.

13 Tiggemann M, Slater A: Thin ideals in music television: a source of social comparison and body dissatisfaction. Int J Eat Disord 2004;35:48-58.

14 McCabe MP, Ricciardelli LA: Body image dissatisfaction among males across the lifespan: a review of past literature. J Psychosom Res 2004;56:675-685.

15 Tiggemann M: Body image across the adult life span: stability and change. Body Image 2004;1:29-41.

16 Grogan S: Body image and health: contemporary perspectives. J Health Psychol 2006;11:523-530.

17 Hill AJ, Williams J: Psychological health in a non-clinical sample of obese women. Int J Obes Relat Metab Disord 1998;22:578-583.

18 Stice E, Shaw HE: Role of body dissatisfaction in the onset and maintenance of eating pathology. J Psychosom Res 2002;53:985-993.

19 Sarwer DB, Wadden TA, Foster GD: Assessment of body image dissatisfaction in obese women: specificity, severity, and clinical significance. J Consult Clin Psychol 1998;66:651-654.

20 Vieira PN, Palmeira AL, Mata J, Kolotkin RL, Silva MN, Sardinha LB, Teixeira PJ: Usefulness of standard BMI cut-offs for quality of life and psychological well-being in women. Obes Facts 2012;5:795-805.

21 Rodin J, Silberstein L, Striegel-Moore R: Women and weight: a normative discontent. Nebr Symp Motiv 1984; 32:267-307.

22 McLaren L, Kuh D: Body dissatisfaction in midlife women. J Women Aging 2004;16:35-54.

23 Feingold A, Mazzella R: Gender differences in body image are increasing. Psychol Sci 1998;9:190-195. 
Weinberger et al.: Body Dissatisfaction in Individuals with Obesity Compared to Normal-Weight Individuals: A Systematic Review and Meta-Analysis

24 Muth JL, Cash TF: Body-image attitudes: what difference does gender make? J Appl Soc Psychol 1997;27: 1438-1452.

25 Tacconelli E: Systematic reviews: CRD's guidance for undertaking reviews in health care. Lancet Infect Dis 2010;10:226.

26 Moher D, Liberati A, Tetzlaff J, Altman DG: Preferred reporting items for systematic reviews and meta-analyses: the PRISMA statement. J Clin Epidemiol 2009;62:1006-1012.

27 World Health Organization: Obesity: preventing and managing the global epidemic. Report of a WHO consultation. WHO Techn Rep Ser 2000;894:i-xii, 1-253.

28 Higgins JPT (ed): Cochrane Handbook for Systematic Reviews of Interventions. Chichester, Wiley-Blackwell, 2008.

29 Morotti E, Battaglia B, Paradisi R, Persico N, Zampieri M, Venturoli S, Battaglia C: Body mass index, Stunkard Figure Rating Scale, and sexuality in young Italian women: a pilot study. J Sex Med 2013;10:1034-1043.

30 Kakeshita IS, de Sousa Almeida S: Relationship between body mass index and self-perception among university students. Rev Saude Publica 2006;40:497-504.

31 Johnstone AM, Stewart AD, Benson PJ, Kalafati M, Rectenwald L, Horgan G: Assessment of body image in obesity using a digital morphing technique. J Hum Nutr Diet 2008;21:256-267.

32 Herbozo S, Menzel JE, Thompson JK: Differences in appearance-related commentary, body dissatisfaction, and eating disturbance among college women of varying weight groups. Eat Behav 2013;14:204-206.

33 Lipowska M, Lipowski M: Narcissism as a moderator of satisfaction with body image in young women with extreme underweight and obesity. PLoS One 2015;10:e126724.

34 McCabe MP, McGreevy SJ: Role of media and peers on body change strategies among adult men: is body size important? Eur Eat Disord Rev 2011;19:438-446.

35 Hrabosky JI, Grilo CM: Body image and eating disordered behavior in a community sample of Black and Hispanic women. Eat Behav 2007;8:106-114.

36 Cash TF: The Multidimensional Body-Self Relations Questionnaire, 3rd ed. 2000. Available from the author at www.body-images.com.

37 Baceviciene M, Reklaitiene R, Tamosiunas A: Effect of excess body weight on quality of life and satisfaction with body image among middle-aged Lithuanian inhabitants of Kaunas city. Medicina (Kaunas) 2009;45:565573.

38 Watkins JA, Christie C, Chally P: Relationship between body image and body mass index in college men. J Am Coll Health 2008;57:95-100.

39 Stunkard AJ, Sorensen T, Schulsinger F: Use of the Danish Adoption Register for the study of obesity and thinness. Res Publ Assoc Res Nerv Ment Dis1983;60:115-120.

40 World Health Organization: WHOQOL User Manual. Geneva, World Health Organization, 1998 www.who.int/ mental_health/evidence/who_qol_user_manual_98.pdf(last accessed December 12, 2016).

41 Fallon EA, Harris BS, Johnson P: Prevalence of body dissatisfaction among a United States adult sample. Eat Behav 2014;15:151-158.

42 Garner DM: The Eating Disorder Inventory-3: Professional Manual. Odessa, Psychological Assessment Resources, Inc., 2004.

43 Cooper PJ, Taylor MJ, Cooper Z, Fairbum CG: The development and validation of the body shape questionnaire. Int J Eat Disord 1987;6:485-494.

44 Jun EM, Choi SB: Obesity, body image, depression, and weight-control behaviour among female university students in Korea. J Cancer Prev 2014;19:240-246.

45 Mendelson BK, Mendelson MJ, White DR: Body-esteem scale for adolescents and adults. J Pers Assess 2001; 76:90-106.

46 Franzoi SL, Shields SA: The Body Esteem Scale: multidimensional structure and sex differences in a college population. J Pers Assess 1984;48:173-178.

47 Ricciardelli LA, McCabe MP: Psychometric evaluation of the Body Change Inventory: an assessment instrument for adolescent boys and girls. Eat Behav 2002;3:45-59.

48 Streeter VM, Milhausen RR, Buchholz AC: Body image, body mass index, and body composition in young adults. Can J Diet Pract Res 2012;73:78-83.

49 Benkeser RM, Biritwum R, Hill AG: Prevalence of overweight and obesity and perception of healthy and desirable body size in urban, Ghanaian women. Ghana Med J 2012;46:66-75.

50 Cachelin FM, Monreal TK, Juarez LC: Body image and size perceptions of Mexican American women. Body Image 2006;3:67-75.

51 Gilbert-Diamond D, Baylin A, Mora-Plazas M, Villamor E: Correlates of obesity and body image in Colombian women. J Womens Health 2009;18:1145-1151.

52 Santos Silva DA, Nahas MV, de Sousa TF, Del Duca GF, Peres KG: Prevalence and associated factors with body image dissatisfaction among adults in southern Brazil: a population-based study. Body Image 2011;8:427431.

53 Stewart AD, Benson PJ, Michanikou EG, Tsiota DG, Narli MK: Body image perception, satisfaction and somatotype in male and female athletes and non-athletes: results using a novel morphing technique. J Sports Sci 2003;21:815-823.

54 Cash TF, Szymanski ML: The development and validation of the Body-Image Ideals Questionnaire. J Pers Assess 1995; 64:466-477. 
Weinberger et al.: Body Dissatisfaction in Individuals with Obesity Compared to Normal-Weight Individuals: A Systematic Review and Meta-Analysis

55 Williamson DA, Davis CJ, Bennett SM, Goreczny AJ, Gleaves DH: Development of a simple procedure for assessing body image disturbances. Behav Assess 1989;11:433-446.

56 Fairburn CG, Beglin SJ: Assessment of eating disorders: interview or self-report questionnaire? Int J Eat Disord 1994;16:363-370.

57 Beck AT, Steer R: Manual for revised Beck Depression Inventory. New York, Psychological Corporation, 1987.

58 Reed DL, Thompson JK, Brannick MT, Sacco WP: Development and validation of the Physical Appearance State and Trait Anxiety Scale (PASTAS). J Anxiety Disord 1991;5:323-332.

59 Zung WW: A self-rating depression scale. Arch Gen Psychiatry 1965;12:63-70.

60 American Psychiatric Association: Diagnostic and Statistical Manual of Mental Disorders, 4th ed (Text Revision). Washington DC, American Psychiatric Association, 2000.

61 Cash TF, Melnyk SE, Hrabosky JI: The assessment of body image investment: an extensive revision of the appearance schemas inventory. Int J Eat Disord 2004;35:305-316.

62 Grilo CM, Masheb RM: Correlates of body image dissatisfaction in treatment-seeking men and women with binge eating disorder. Int J Eat Disord 2005;38:162-166.

63 Inchley J, Currie D, Young T, Samdal O, Torsheim T, Augustson L, Mathison F, Aleman-Diaz A, Molcho, M, Weber M, Barnekow V (eds): Health Policy for Children and Adolescents, No. 7. Growing up unequal: gender and socioeconomic differences in young people's health and well-being. Health Behaviour in School-Aged Children (HBSC) Study: International Report from the 2013/2014 Survey.Copenhagen: WHO Regional Office for Europe, 2016. www.euro.who.int/_data/assets/pdf_file/0003/303438/HSBC-No7-Growing-up-unequal-fullreport.pdf (last accessed December 12, 2016).

64 McCreary, Sasse DK: An exploration of the drive for muscularity in adolescent boys and girls. J Am College Health 2000;48:297-304.

65 Cafri G, Thompson JK, Ricciardelli L, McCabe M, Smolak L, Yesalis C: Pursuit of the muscular ideal: physical and psychological consequences and putative risk factors. Clin Psychol Rev 2005;25:215-239.

66 Wright S, Grogan S, Hunter G: Motivations for anabolic steroid use among bodybuilders. J Health Psychol 2000; 5:566-571.

67 Puhl RM, Heuer CA. The stigma of obesity: a review and update. Obesity (Silver Spring) 2009;17:941-964.

68 Sarwer D, Thompson JK: Obesity and body image disturbance; in Wadden TA, Stunkard AJ (eds): Handbook of Obesity Treatment. New York, Guilford Press, 2002, pp 447-464.

69 de Zwaan M, Georgiadou E, Stroh CE, Teufel M, Köhler H, Tengler M, Müller A: Body image and quality of life in patients with and without body contouring surgery following bariatric surgery: a comparison of pre- and post-surgery groups. Front Psychol 2014;5:1310.

70 Heinberg LJ, Thompson JK, Matzon J: Body image dissatisfaction as a motivator for healthy lifestyle change: Is some distress beneficial? in Striegel-Moore RH, Smolak L (eds): Eating Disorders: Innovative Directions in Research and Practice. Washington, DC, American Psychological Association, 2001, pp 215-232.

71 Palmeira AL, Branco TL, Martins SC, Minderico CS, Silva MN, Vieira PN, Barata JT, Serpa SO, Sardinha LB, Teixeira PJ: Change in body image and psychological well-being during behavioral obesity treatment: associations with weight loss and maintenance. Body Image 2010;7:187-193.

72 Thompson JK, Altabe MN: Psychometric qualities of the figure rating scale. Int J Eat Disord 1991;10:615-619.

73 Higgins ET: Self-discrepancy: a theory relating self and affect. Psychol Rev 1987;94:319-340.

74 Cafri G, van den Berg P, Brannick MT: What have the difference scores not been telling us? A critique of the use of self-ideal discrepancy in the assessment of body image and evaluation of an alternative data-analytic framework. Assessment 2010;17:361-376.

75 Gorber SC, Tremblay M, Moher D, Gorber B: A comparison of direct vs. self-report measures for assessing height, weight and body mass index: a systematic review. Obes Rev 2007;8:307-326.

76 Niedhammer I, Bugel I, Bonenfant S, Goldberg M, Leclerc A: Validity of self-reported weight and height in the French GAZEL cohort. Int J Obes Relat Metab Disord 2000;24:1111-1118.

77 Nawaz H, Chan W, Abdulrahman M, Larson D, Katz DL: Self-reported weight and height: implications for obesity research. Am J Prevent Med 2001;20:294-298.

78 Williams EP, Mesidor M, Winters K, Dubbert PM, Wyatt SB: Overweight and obesity: prevalence, consequences, and causes of a growing public health problem. Curr Obes Rep 2015;4:363-370.

79 Wardle J, Waller J, Rapoport L: Body dissatisfaction and binge eating in obese women: the role of restraint and depression. Obes Res 2001;9:778-787. 